\title{
Temporal estimates of case-fatality rate for COVID-19 outbreaks in Canada and the United States
}

\author{
Elaheh Abdollahi MSc, David Champredon PhD, Joanne M. Langley MD, Alison P. Galvani PhD, \\ Seyed M. Moghadas PhD
}

Cite as: CMAJ 2020 June 22;192:E666-70. doi: 10.1503/cmaj.200711; early-released May 22, 2020

\begin{abstract}
BACKGROUND: Estimates of the casefatality rate (CFR) associated with coronavirus disease 2019 (COVID-19) vary widely in different population settings. We sought to estimate and compare the COVID-19 CFR in Canada and the United States while adjusting for 2 potential biases in crude CFR.
\end{abstract}

METHODS: We used the daily incidence of confirmed COVID-19 cases and deaths in Canada and the US from Jan. 31 to Apr. 22, 2020. We applied a statistical method to minimize bias in the crude CFR by accounting for the survival inter- val as the lag time between disease onset and death, while considering reporting rates of COVID-19 cases less than 50\% (95\% confidence interval 10\%-50\%).

RESULTS: Using data for confirmed cases in Canada, we estimated the crude CFR to be $4.9 \%$ on Apr. 22, 2020 , and the adjusted CFR to be $5.5 \%$ (credible interval [Crl] 4.9\%-6.4\%). After we accounted for various reporting rates less than $50 \%$, the adjusted CFR was estimated at $1.6 \%$ (Crl $0.7 \%-3.1 \%)$. The US crude CFR was estimated to be $5.4 \%$ on Apr. 20, 2020, with an adjusted CFR of $6.1 \%$ (Crl 5.4\%-6.9\%). With reporting rates of less than $50 \%$, the adjusted CFR for the US was 1.78 ( $\mathrm{Crl} \mathrm{0.8 \% -3.6 \% ).}$

INTERPRETATION: Our estimates suggest that, if the reporting rate is less than $50 \%$, the adjusted CFR of COVID-19 in Canada is likely to be less than $2 \%$. The CFR estimates for the US were higher than those for Canada, but the adjusted CFR still remained below $2 \%$. Quantification of case reporting can provide a more accurate measure of the virulence and disease burden of severe acute respiratory syndrome coronavirus 2 .
T he risk of death associated with severe acute respiratory syndrome coronavirus 2 (SARS-CoV-2) is fundamental to the disease burden imposed by the coronavirus disease 2019 (COVID-19) pandemic. Quantification of this risk can provide critical information on the health and socioeconomic impact of the pandemic and identify population subgroups at highest risk for severe outcomes. The risk of death from a diagnosed infection, often referred to as the casefatality rate (CFR), is the proportion of people who die from a disease among all those diagnosed with the disease over a certain period.

Estimates of the COVID-19 CFR vary in different populations and at different stages of the outbreak, ranging from $0.4 \%$ in China $^{1}$ to $31.4 \%$ in the northwest region of Italy. ${ }^{2}$ From individual-level data for patients in Hubei Province, Mainland China, ${ }^{3}$ an adjusted CFR of 3.6\% (95\% confidence interval [CI] $3.6 \%-3.8 \%$ ) was estimated. For the outbreak on the Diamond
Princess cruise ship, the age-adjusted CFR was estimated at 2.6\% $(95 \% \mathrm{Cl} 0.9 \%-6.7 \%)$ in all age groups but was substantially higher $(13.0 \%$, 95\% $\mathrm{Cl}$ 5.2\%-26.0\%) among those aged 70 years or older. ${ }^{4}$

For ongoing outbreaks and especially during the exponential growth phase, the delay between onset of disease and knowledge of the final outcome may result in biased estimates of the CFR. ${ }^{5}$ Furthermore, underestimation of the number of COVID-19 cases will inflate the CFR. Limited ability to test or recognize mildly or moderately symptomatic people in both the United States and Canada has likely led to substantial underestimation of the rate of infection in affected communities. ${ }^{6,7}$

Given the importance of the CFR in public health planning, we sought to estimate the CFR for ongoing COVID-19 outbreaks in the US and Canada while accounting for preferential ascertainment of severe cases (leading to underestimation) and the lag time between disease onset and death. 


\section{Methods}

We extracted the daily incidence of confirmed cases and deaths associated with COVID-19 (Figure 1A, Figure 2A) from Jan. 31 to Apr. 22, 2020..$^{8-10}$ The crude CFR, based on confirmed cases at any point in time, is (total number of deaths [t]/total number of cases [t] $\times 100$. However, at any point in time during an ongoing outbreak, people who have died from infection will not represent the total number of deaths among those who are infected. The denominator of the CFR also includes infected people who have

A

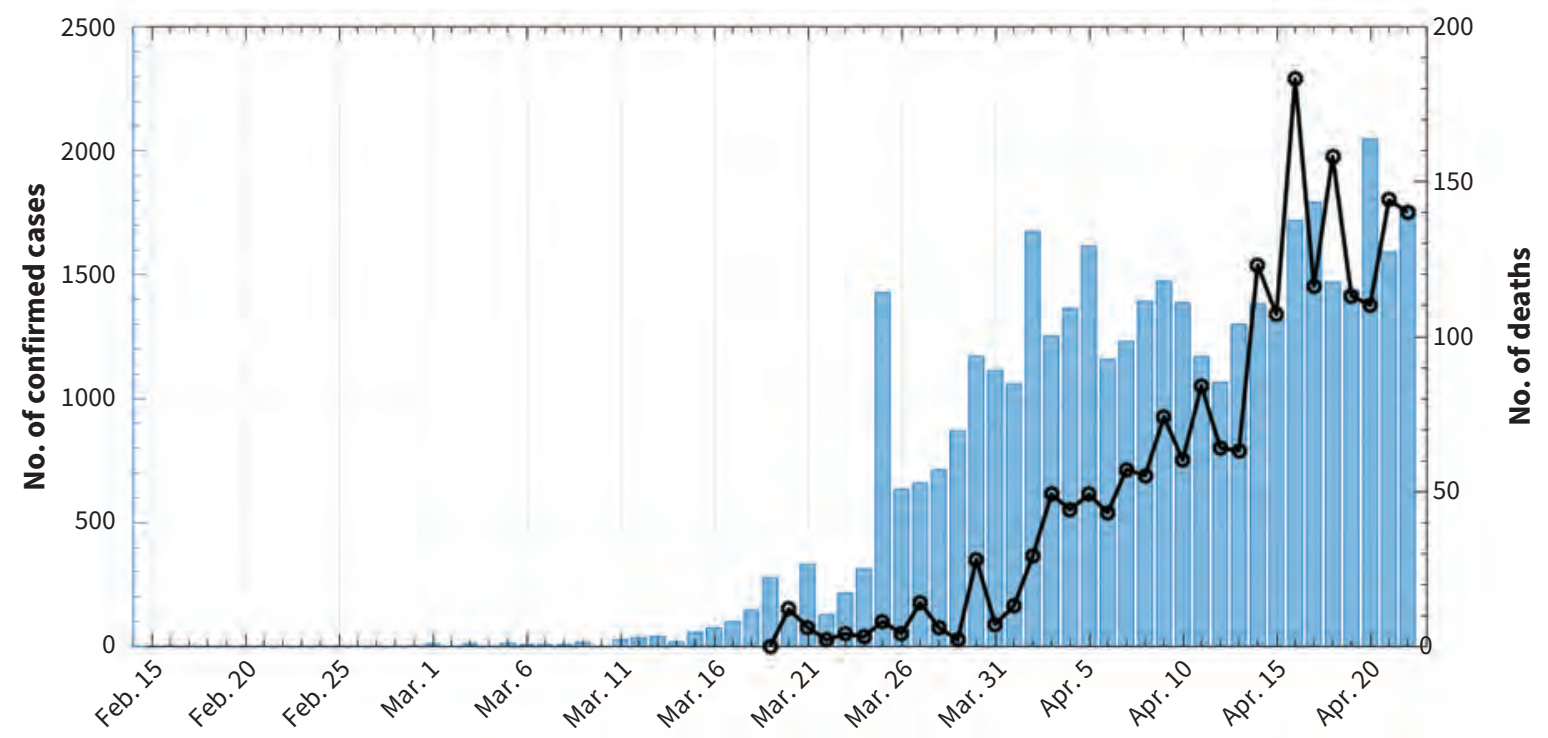

Date

B

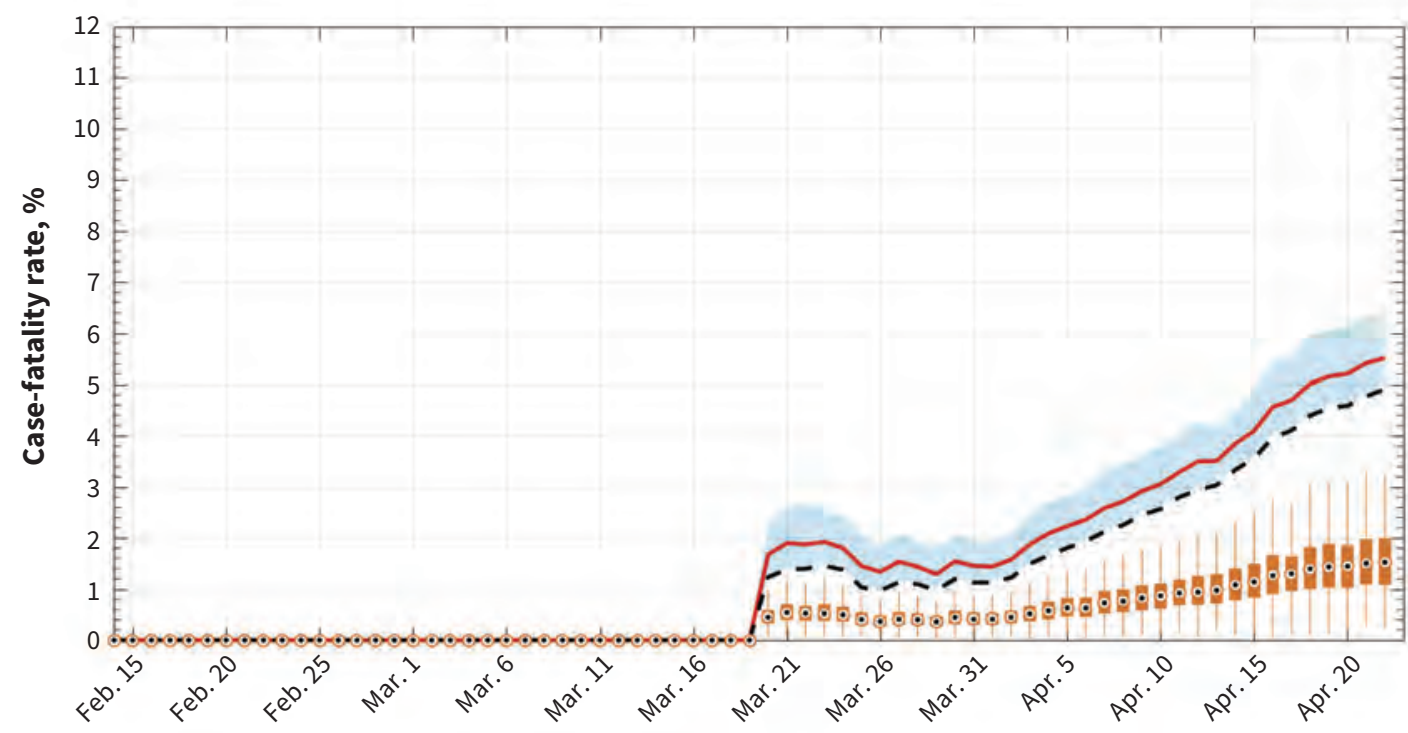

Date

Figure 1: (A) Daily incidence of coronavirus disease 2019 (bars) and associated deaths (black line) in Canada, 2020. (B) Crude case-fatality rate (CFR) (dashed line) and adjusted CFR estimates (red line) from Mar. 19 to Apr. 22, 2020. The shaded area around the red line illustrates the $95 \%$ credible interval for the adjusted CFR. Boxplots show the range of adjusted CFR estimates when the probability of reporting was less than 0.5 ( $95 \%$ confidence interval $0.1-0.5)$. Boxes indicate interquartile range (IQR), and lines indicate extended range from minimum (25th percentile - $1.5 \mathrm{IQR})$ to maximum (75th percentile + 1.5 IQR). 
A

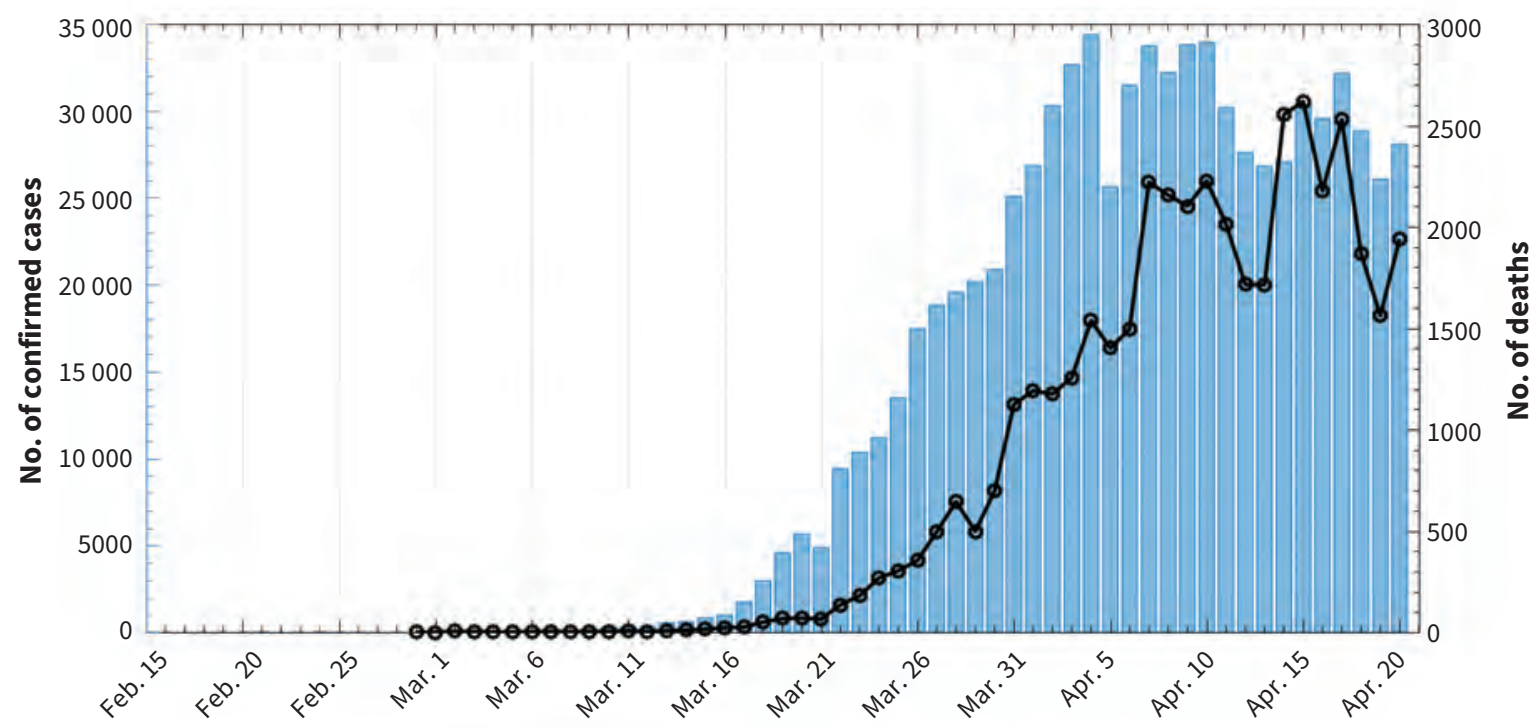

Date

B

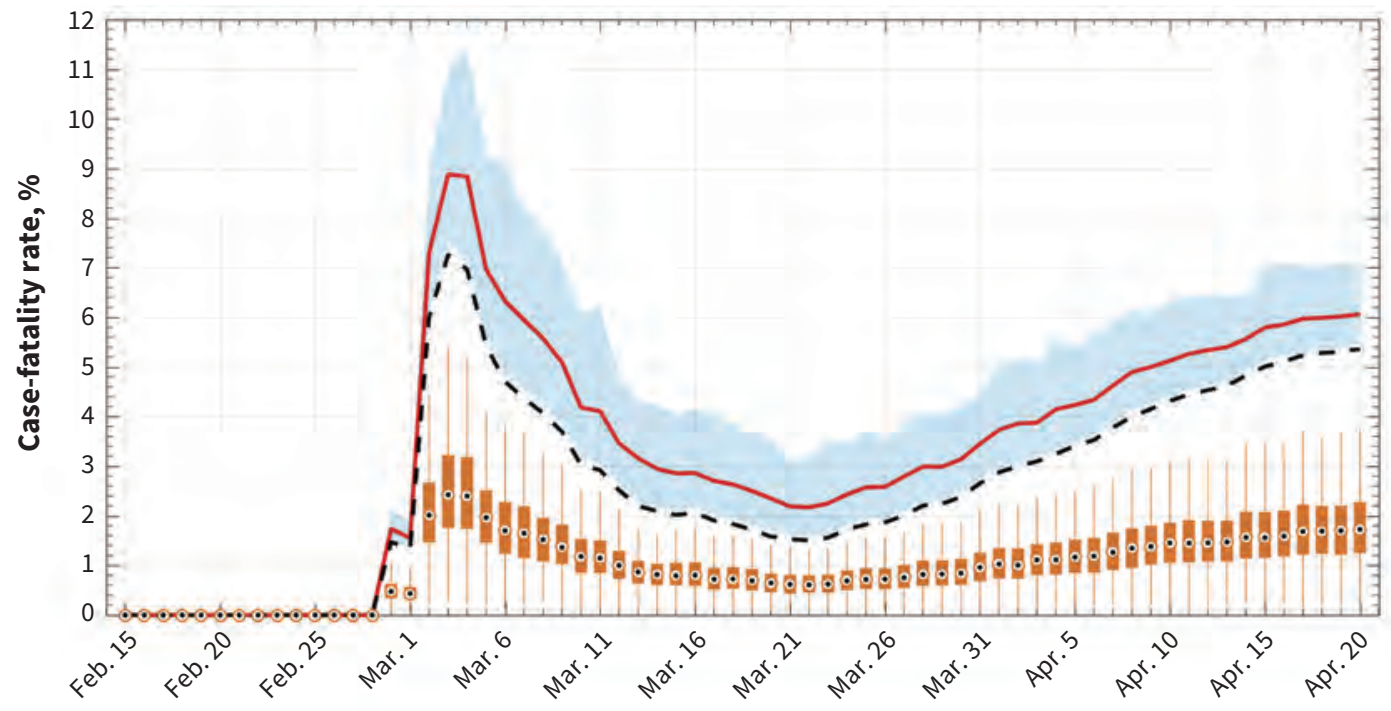

Date

Figure 2: (A) Daily incidence of coronavirus disease 2019 (bars) and associated deaths (black line) in the United States, 2020. (B) Crude case-fatality rate (CFR) (dashed line) and adjusted CFR estimates (red line) from Feb. 28 to Apr. 20, 2020. The shaded area around the red line illustrates the 95\% credible interval for the adjusted CFR. Boxplots show the range of adjusted CFR estimates when the probability of reporting was less than 0.5 ( $95 \%$ confidence interval $0.1-0.5)$. Boxes indicate interquartile range (IQR), and lines indicate extended range, from minimum (25th percentile - $1.5 \mathrm{IQR})$ to maximum (75th percentile $+1.5 \mathrm{IQR}$ ).

not yet died from the infection but will do so at some point in the future. Thus, a source of bias in calculating the CFR arises from the lag time between infection and death.

To minimize this bias, we applied a statistical method that accounts for the uncertainty associated with different lag times from disease onset to death, by allowing the probabilistic distri- bution of the survival interval to vary within a broad range (see Appendix 1, available at www.cmaj.ca/lookup/suppl/doi:10. 1503/cmaj.200711/-/DC1, for technical details). Given the possibility of underreporting of disease owing to mild or asymptomatic illness that does not come to medical attention or is not laboratory confirmed, we also estimated the CFR under the 
assumption of reporting rates less than $50 \%(95 \% \mathrm{Cl} 10 \%-$ $50 \%) .{ }^{11,12}$ We obtained the credible interval $(\mathrm{Crl})$ values for CFR estimates from the profile likelihood to account for the uncertainty in the adjusted CFR values.

\section{Ethics approval}

This research was based on publicly available data and did not require ethics approval.

\section{Results}

The crude CFR in Canada was estimated at $4.9 \%$ on Apr. 22, 2020. When we accounted for the survival interval, the adjusted CFR was 5.5\% (Crl 4.9\%-6.4\%) (Figure 1B). However, when we considered the reporting rates of confirmed cases, we estimated a further adjusted CFR of $1.6 \%$ ( $\mathrm{Crl} 0.7 \%-3.1 \%)$ on the same date by fitting a log-normal distribution to the simulated data points (Figure 1B). Our CFR estimates for the US were higher than those for Canada: the US crude CFR was estimated at $5.4 \%$ on Apr. 20, 2020, and the adjusted CFR was $6.1 \%(\mathrm{Crl}$ $5.4 \%-6.9 \%$ ) (Figure $2 \mathrm{~B}$ ). For the range of reporting rates considered here, the adjusted CFR was estimated at $1.8 \%(\mathrm{Crl}$ $0.8 \%-3.6 \%$ ) on Apr. 20, 2020.

\section{Interpretation}

Our estimates suggest that, if the reporting rates of COVID-19 cases are less than $50 \%$ in Canada, the adjusted CFR is likely to be less than 2\%. Estimates of the adjusted CFR for the US were slightly higher than those for Canada but still remained below $2 \%$. We note that the CFR at the regional or city level may be different from country-level estimates. For example, using the same methodology, we found that the crude CFR for New York City was $7.2 \%$ and the adjusted CFR was 7.8\% (Crl 7.2\%-8.8\%) on Apr. 20, 2020. On the same date, the adjusted CFR with the reporting rate interval was estimated at $2.2 \%(\mathrm{Crl} 0.9 \%-4.5 \%)$ (unpublished data, 2020).

Reasons for the variability in CFR estimates in different countries during COVID-19 outbreaks reported in the present study and by Rajgor and colleagues ${ }^{13}$ merit further study. For example, CFR estimates in similar geographic and climate conditions such as western Pacific islands vary widely, from $0.39 \%$ (Singapore) to $7.14 \%$ (Philippines). ${ }^{14} \mathrm{~A}$ meta-analysis of studies that estimated the COVID-19 CFR showed that $13.5 \%$ (95\% CI 6.2\%-21.5\%) of inpatients died. ${ }^{15}$ In another study, an estimated CFR of $67 \%$ was reported in critically ill patients. ${ }^{16,17}$ The CFR will vary according to the population considered, such as that in a critical care setting, a general hospital or a long-term care facility. ${ }^{18-20}$ These influences and other host, environment and exposure variables that alter CFRs merit further study.

\section{Limitations}

The CFR is influenced by the demographic and comorbidity composition of the population, the availability and preparedness of the health care system, and differences in the diagnosis, treatment, prevention and control policies implemented in different countries. The CFRs presented in the current study refer to the entire population of Canada and the US. Case-fatality rates may be higher among those with risk factors for severe disease, in populations with a higher proportion of older adults, or in settings without prepared health care systems or adequate resources to care for a surge of cases. ${ }^{18-20}$ Estimates of CFR also depend on other factors such as the reporting rate, which may be affected by testing capacity and characteristics of the disease. Our CFR estimates are implicitly subject to these factors and may change with quantification of these factors and additional data over time as the pandemic evolves.

\section{Conclusion}

During the early stages of an emerging outbreak, when not all cases are resolved or reported, improving crude CFR estimates by removing sources of bias can provide preliminary information for public health professionals and policy-makers on the population burden of disease. Further studies are needed to quantify the reporting rates given the possibility of asymptomatic infection, the underdiagnosis of COVID-19 cases owing to mild illness, and province-, country- or region-specific rates. This quantification can improve CFR estimates to provide a more accurate measure of virulence for SARS-CoV-2 as it spreads through the populations in Canada and the US.

\section{References}

1. Wang X, Ma Z, Ning Y, et al. Estimating the case fatality ratio of the COVID-19 epidemic in China. medRxiv 2020 Mar 3. doi: 10.1101/2020.02.17.20023630.

2. Mizumoto K, Dahal S, Chowell G. Spatial variability in the risk of death from COVID-19 in Italy, 2020. medRxiv 2020 Apr. 16. doi: 10.1101/2020.04.01.20049668.

3. Verity R, Okell LC, Dorigatti I, et al. Estimates of the severity of coronavirus disease 2019: a model-based analysis [published erratum in Lancet Infect Dis 2020 Apr. 15 [Epub ahead of print]. pii: S1473-3099(20)30309-1. doi: 10.1016/S14733099(20)30309-1; Lancet Infect Dis 2020 May 4 [Epub ahead of print]. pii: S14733099(20)30368-6. doi: 10.1016/S1473-3099(20)30368-6]. Lancet Infect Dis 2020 Mar. 30 [Epub ahead of print]. pii: S1473-3099(20)30243-7. doi: 10.1016/ S1473-3099(20)30243-7.

4. Russell TW, Hellewell J, Jarvis $\mathrm{CI}$, et al. Estimating the infection and case fatality ratio for coronavirus disease (COVID-19) using age-adjusted data from the outbreak on the Diamond Princess cruise ship. Euro Surveill 2020;25. doi: 10.2807/1560-7917.ES.2020.25.12.2000256

5. Garske T, Legrand J, Donnelly CA, et al. Assessing the severity of the novel influenza A/H1N1 pandemic. BMJ 2009;339:b2840.

6. Bendavid E, Mulaney B, Sood N, et al. COVID-19 antibody seroprevalence in Santa Clara County, California. medRxiv 2020 Apr. 30. doi: 10.1101/2020.04.14. 20062463.

7. Imai N, Dorigatti I, Cori A, et al. Estimating the potential total number of novel Coronavirus cases in Wuhan City, China. London (UK): Imperial College London; 2020. Available: https://www.imperial.ac.uk/media/imperial-college/medicine/ sph/ide/gida-fellowships/Imperial-College-COVID19-epidemic-size-17-01-2020. pdf (accessed 2020 Jan. 25).

8. Coronavirus disease (COVID-19): outbreak update. Ottawa: Public Health Agency of Canada; modified 2020 May 18. Available: https://www.canada.ca/en/public -health/services/diseases/2019-novel-coronavirus-infection.html?topic=tilelink (accessed 2020 May 19).

9. Coronavirus cases in the United States. Worldometer. Available: www. worldometers.info/coronavirus/country/us/ (accessed 2020 Apr. 25).

10. COVID-19: data. New York: NYC Health. Available: www1.nyc.gov/site/doh/ covid/covid-19-data.page (accessed 2020 Apr. 25).

11. Gilmour S, Yoneoka D, Wang Y, et al. A Bayesian estimate of the underreporting rate for COVID-19 based on the experience of the Diamond Princess cruise ship. Bull World Health Organ 2020 Mar. 12 [Epub ahead of print]. doi: 10.2471/ BLT.20.254565.

12. Russell TW, Hellewell J, Abbott S, et al. Using a delay-adjusted case fatality ratio to estimate under-reporting. London (UK): Centre for Mathematical 
Modeling of Infectious Diseases, London School of Hygiene \& Tropical Medicine; 2020 Mar. 22, updated 2020 May 19. Available: https://cmmid.github.io/ topics/covid19/global_cfr_estimates.html (accessed 2020 May 19).

13. Rajgor DD, Lee MH, Archuleta S, et al. The many estimates of the COVID-19 case fatality rate. Lancet Infect Dis 2020 Mar. 27 [Epub ahead of print]. pii: S14733099(20)30244-9. doi: 10.1016/S1473-3099(20)30244-9.

14. Mei Y, Hu J. Preparedness is essential for Western Pacific islands during the COVID-19 pandemic. Disaster Med Public Health Prep 2020 Apr. 16 [Epub ahead of print]. doi: 10.1017/dmp.2020.102.

15. Rodriguez-Morales AJ, Cardona-Ospina JA, Gutiérrez-Ocampo E, et al.; Latin American Network of Coronavirus Disease 2019-COVID-19 Research (LANCOVID-19). Clinical, laboratory and imaging features of COVID-19: a systematic review and meta-analysis. Travel Med Infect Dis 2020 Mar. 13 [Epub ahead of print. doi: 10.1016/j.tmaid.2020.101623.
16. Bhatraju PK, Ghassemieh BJ, Nichols M, et al. COVID-19 in critically ill patients in the Seattle region - case series. N Engl J Med 2020 Mar. 30 [Epub ahead of print]. doi: 10.1056/NEJMoa2004500.

17. Arentz M, Yim E, Klaff L, et al. Characteristics and outcomes of 21 critically ill patients with COVID-19 in Washington State. JAMA 2020 Mar. 19 [Epub ahead of print]. doi: 10.1001/jama.2020.4326.

18. McMichael TM, Currie DW, Clark S, et al. Epidemiology of COVID-19 in a longterm care facility in King County, Washington. N Engl J Med 2020 Mar. 27 [Epub ahead of print]. doi: 10.1056/NEJMoa2005412.

19. Onder G, Rezza G, Brusaferro S. Case-fatality rate and characteristics of patients dying in relation to COVID-19 in Italy. JAMA 2020 Mar. 23 [Epub ahead of print]. doi: 10.1001/jama.2020.4683.

20. Li LQ, Huang T, Wang YQ, et al. COVID-19 patients' clinical characteristics, discharge rate, and fatality rate of meta-analysis. J Med Virol 2020;92:577-83.
Competing interests: Joanne Langley holds the Canadian Institutes of Health ResearchGlaxoSmithKline Chair in Pediatric Vaccinology at Dalhousie University. Dalhousie University has received funding for research studies from Sanofi Pasteur, Merck, Janssen, VBI and Pfizer. No other competing interests were declared.

This article has been peer reviewed.

Affiliations: Agent-Based Modelling Laboratory (Abdollahi, Moghadas), York University, Toronto, Ont.; Department of Pathology and Laboratory Medicine (Champredon), Western University, London, Ont.; Canadian Center for Vaccinology (Langley), Dalhousie University, IWK Health Centre and Nova Scotia Health Authority (Langley), Halifax, NS; Center for Infectious Disease Modeling and Analysis
(Galvani), Yale School of Public Health, New Haven, Conn.

Contributors: Seyed Moghadas and Alison Galvani conceived and designed the study. Elaneh Abdollahi and David Champredon implemented the simulation and statistical methods. Elaneh Abdollahi analyzed and interpreted the data. Seyed Moghadas, Alison Galvani, David Champredon and Joanne Langley drafted the manuscript and revised it critically for important intellectual content. All of the authors approved the final version to be published and agreed to be accountable for all aspects of the work.

Funding: Seyed Moghadas acknowledges support from the Canadian Institutes of Health Research (OV4-170643; Canadian 2019
Novel Coronavirus Rapid Research) and the Natural Sciences and Engineering Research Council of Canada. Alison Galvani acknowledges support from the National Institutes of Health (UO1-GM087719, 1RO1AI151176-01), Burnett \& Stender Families Endowment and the Notsew Orm Sands Foundation.

Data sharing: Data, statistical methods and computing programs are available at: https:// github.com/Ellie-Abdollahi/CFR-CoViD19.

Accepted: May 13, 2020

Correspondence to: Joanne Langley, Joanne. Langley@dal.ca 